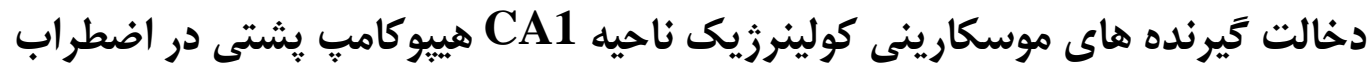

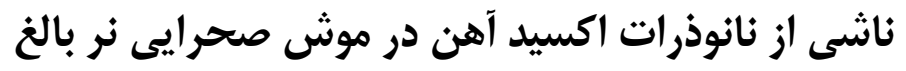

$$
\text { لكف اله خواجه يور'، اعظم كريمى'، مهناز كسمتى'، مزّكان ترابى' }
$$

ا) كروه زيست شناسى، دانشكده علوم، دانشكاه شهيد خِمران (هواز، (هولز، ايرانغ

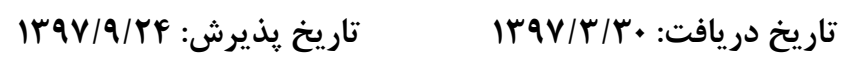

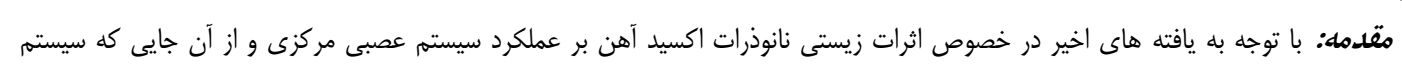

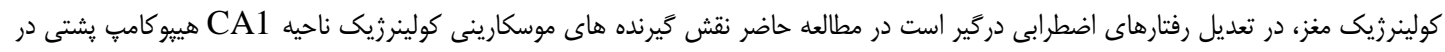

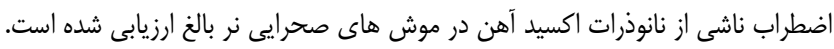

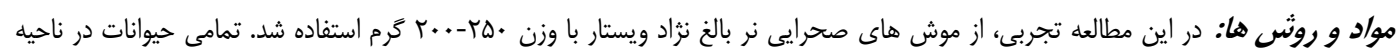

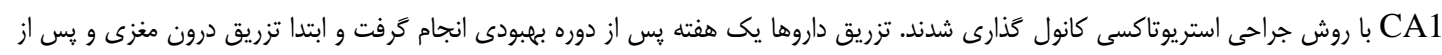

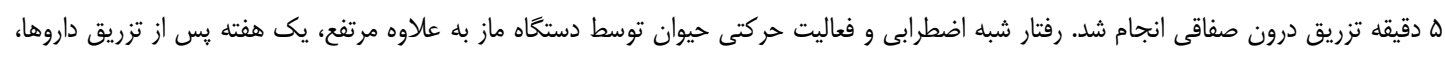

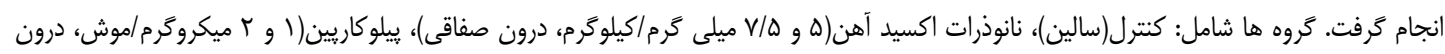

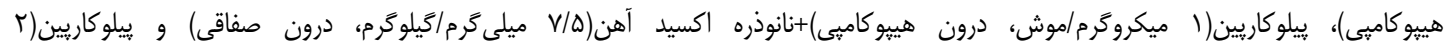

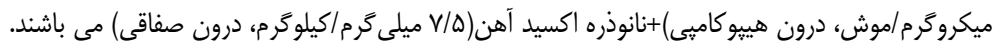

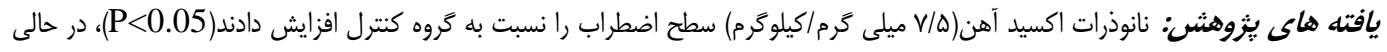

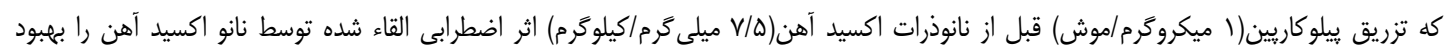
بخشيد(P<0.05).

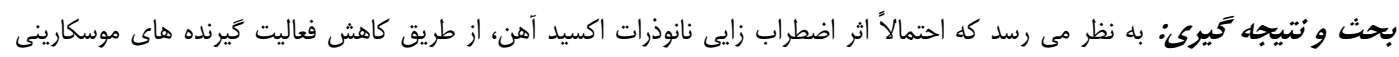
كولينرزيك ناحيه CA1 هييو كامب بشتى ميانجيكًرى مى شود.

وازه هاى كليدى: گَيرنده هاى موسكارينى، هييو كامٍ، اضطراب، نانوذرات اكسيد آهن، موش صحرايى

Email:a_karimi_6813@yahoo.com

Copyright (C) 2019 Journal of Ilam University of Medical Science. This is an open-access article distributed under the terms of the Creative Commons Attribution international 4.0 International License (https://creativecommons.org/licenses/by-nc/4.0/) which permits copy and redistribute the material, in any medium or format, provided the original work is properly cited. 


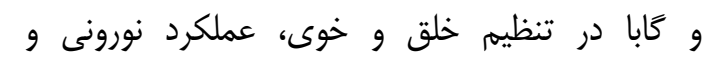

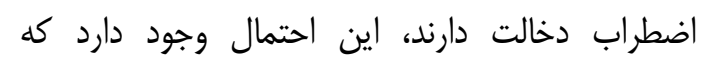

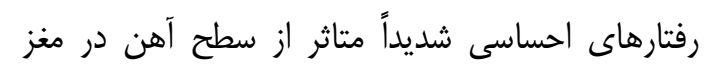

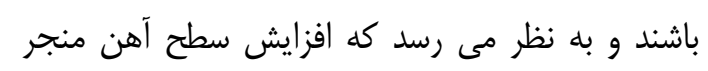

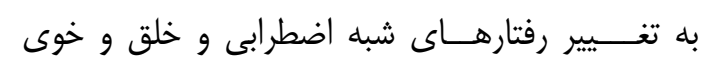

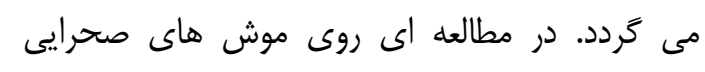

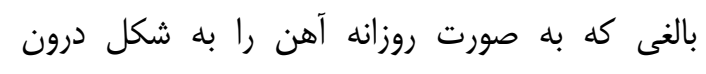

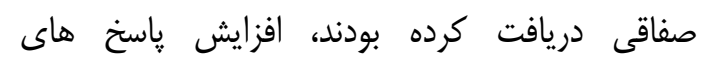

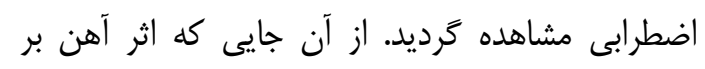
رفتارهاى احساسى به صورت وابسته به مقدار است،

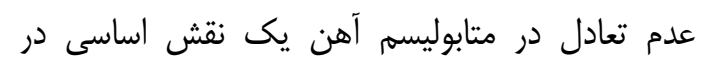

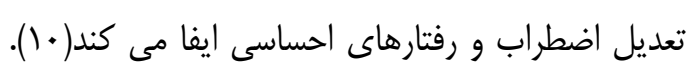

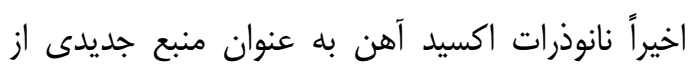

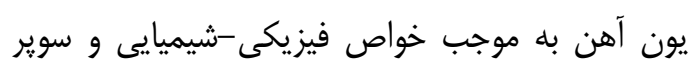

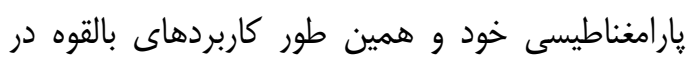

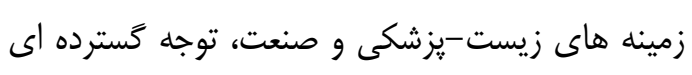

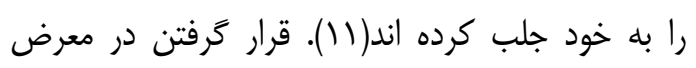

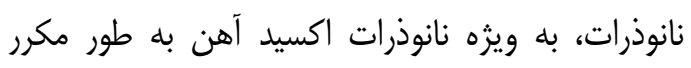

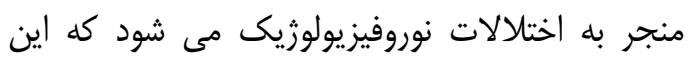
امر به دليل تجمع نانوذرات، استرس اكسيداتيو و آيويتوز

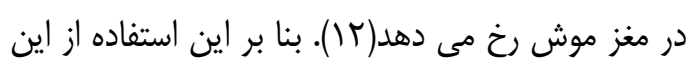

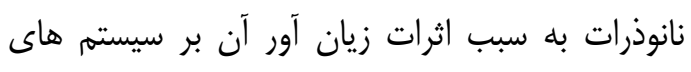

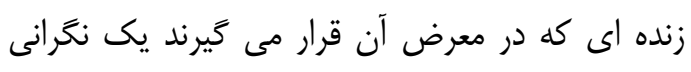

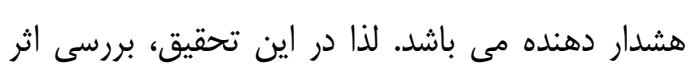

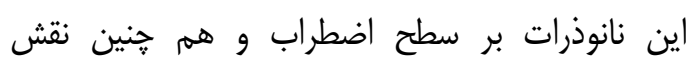

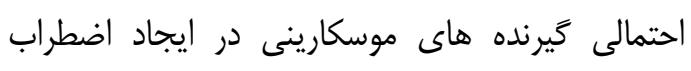

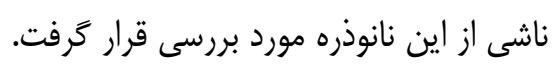

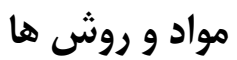

حيوانات آزمايشكاهي: در اين مطالعه از موش هاى

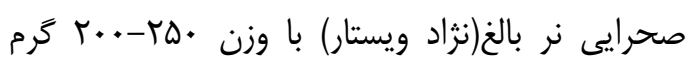

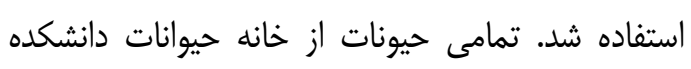

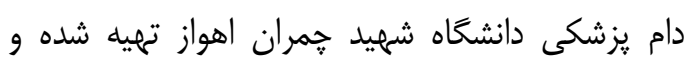

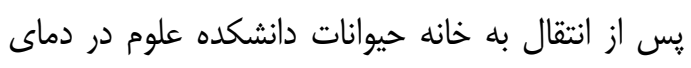

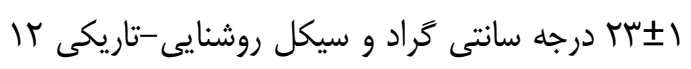

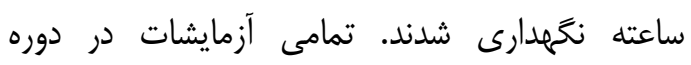

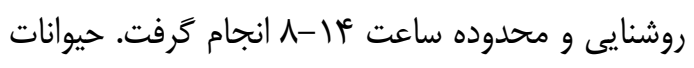

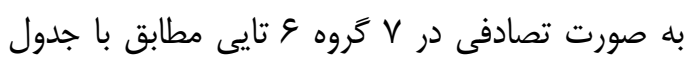

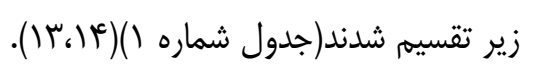

مقدمه اختلالات اضطرابى يكى از شايع ترين بيمارى هاى

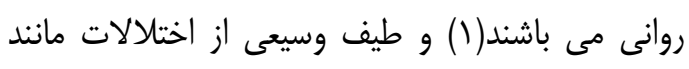

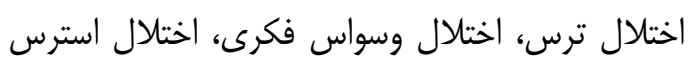

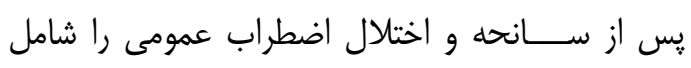

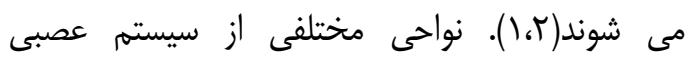

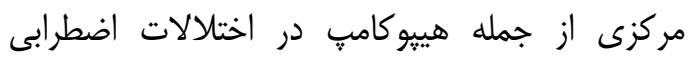

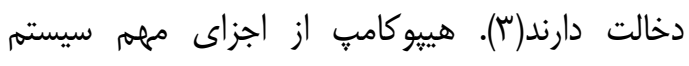
ليمبيك است كه داراى تشكيلات مختلفى از جمله:

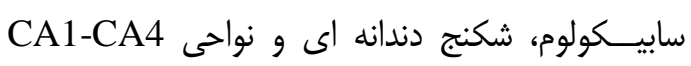

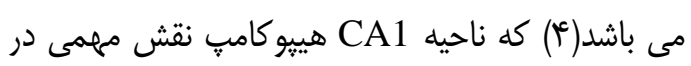
اضطراب دارد(ه). - (ه).

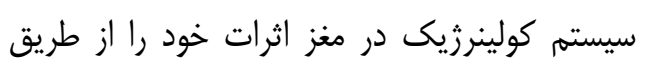
دو نوع گيرنده موسكارينى و نيكوتينى اعمال مى كند و و

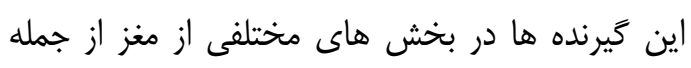

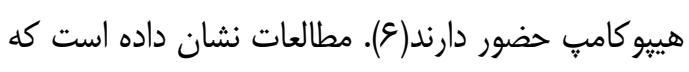
كيرنده هاى موسكارينى در كنترل رفتارهاى اضطرابى دارئ

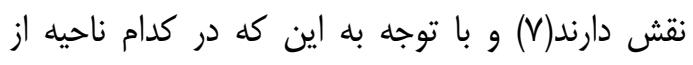

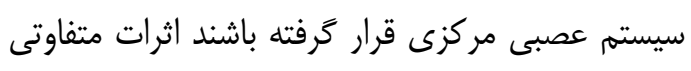

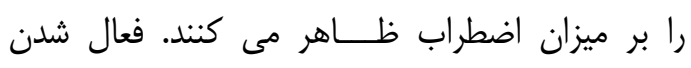

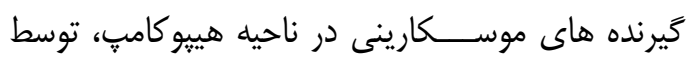
استيل كولين، باعث كاهش ميزان اضطراب درئ در حيوان

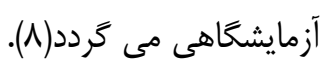

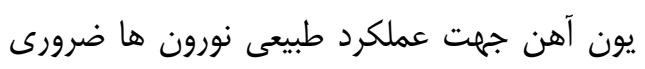
مى باشد(9). اختلال در ميلين سازى كه به به ديه دنبال كمبود آهن در طى مرحل اوليه تكامل اتفاق مى افتلاتل دئل

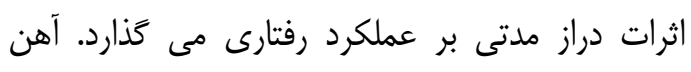
نقش حياتى در هومئوستاز سيستم مونوآمينرزيك،

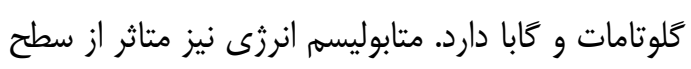

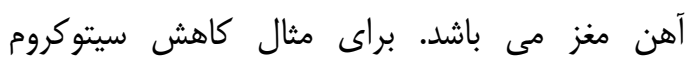
اكسيداز C كه به دنبال فقر آهن در دوران جنينى اتفاق

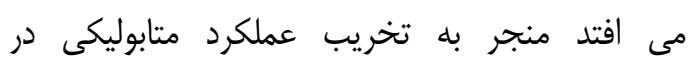

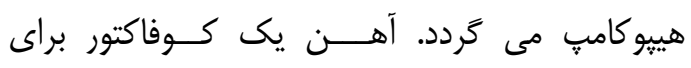
آنزيم هاى هيدو كسيلاز ترييتــــوفان و هــــيدروكسيلاز تيروزين مى باشد كه اين آنزيم ها به ترتيب، مسئول

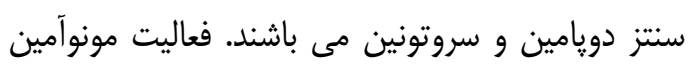

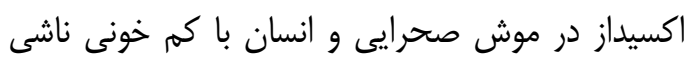

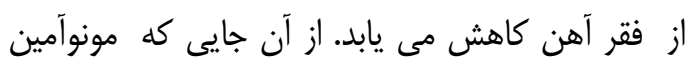




\begin{tabular}{|c|c|c|}
\hline تزريق درون صفاقى & تزريق درون CA1 & كروه ها \\
\hline سالين( (ميلى ليتر /كيلوكرم) & سالين( (ميكروليتر /موش) & اكتترل \\
\hline نانواكسيدآهن(هميلى گَرم/كيلوَّرم) & سالين( اميكروليتر /موش) & ז. دريافت كننده نانواكسيدآهن \\
\hline نانواكسيدآهن(ه/هيلى گرم/كيلوكرم) & سالين( (اميكروليتر /موش) & ז. دريافت كننده نانواكسيدآهن \\
\hline سالين( (ميلى ليتر /كيلوَرم) & ييلو كاريين( (ميكرو كرم/موش) & ז. دريافت كننده يِيبوكاريين \\
\hline سالين(اميلى ليتر /كيلوَّرم) & ييلو كاريين( آميكرو كرم/موش) & ه. دريافت كننده ييلوكاريين \\
\hline نانواكسيدآهن(V/هيلى گرم/ كيلوَّرم) & ييلو كاريين( (ميكرو گرم/موش) & 9. مداخله 1 \\
\hline نانواكسيدآهن(ه/هيلى كرم/كيلوَّرم) & ييلو كاريين(r ميكروگ رم/موش) & 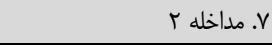 \\
\hline
\end{tabular}

انجام گرفت. جهت تزريق درون مغزى داروها از

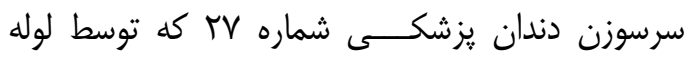
يلى اتيلن به سرنغ هاميلتون متصل شده بون بود استفاده شد. براى هر حيوان ا ميكروليتر دارو به مدت .9 ثانيه تزريق شد. پِ از انجام كليه آزمايشات جهت تاييد صحت مختصات محل جراحى، مقدار 1 ميكروليتر

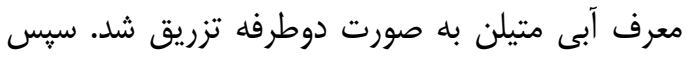

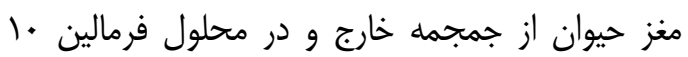

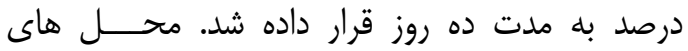

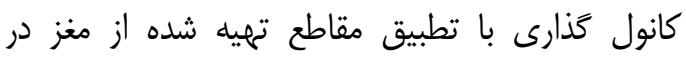

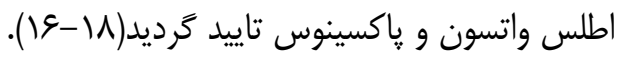

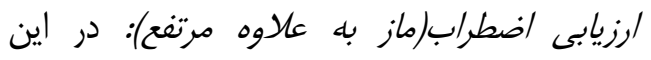
تحقيق جهت بررسى اضطراب، از دستخاه ماز به علاوه

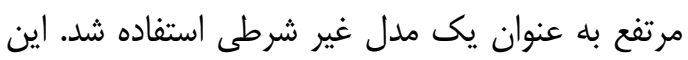

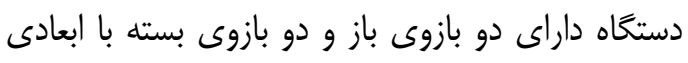

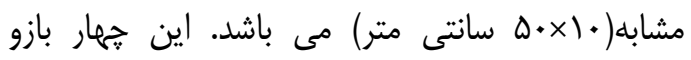

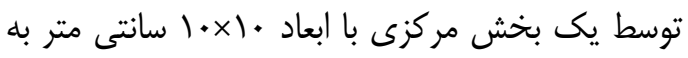

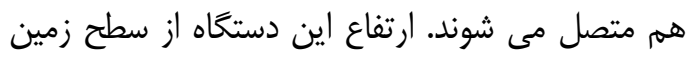

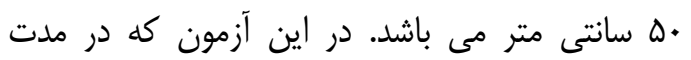

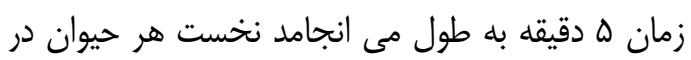

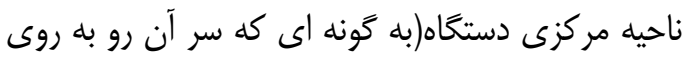

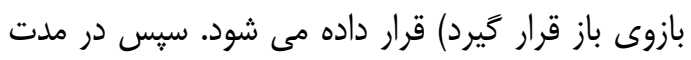

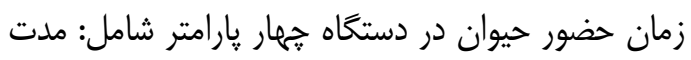

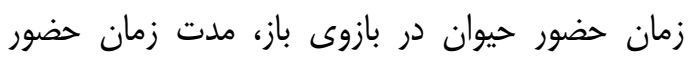
حيوان در بازوى بسته، تعداد دفعات ورود حيوان ديوان بهان

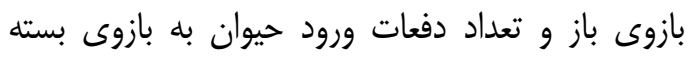

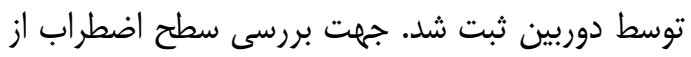

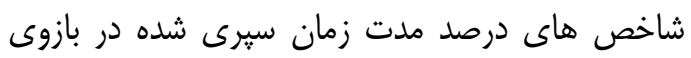

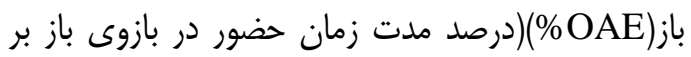
مجموع مدت زمان حضور در بازوى باز و بسته) و بالمان

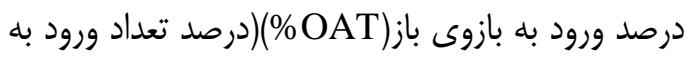

داروها: نانوذرات اكسيد آهن استفاده شده در اين

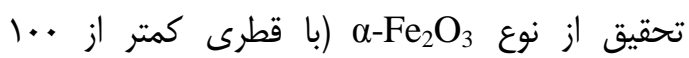
نانومتر) و ساخت مركز تحقيقاتى داخلى بود. اين نانوذره در سرم فيــزيولوزى 9/.

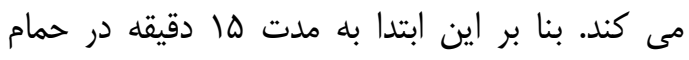

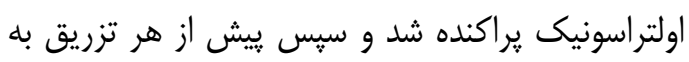

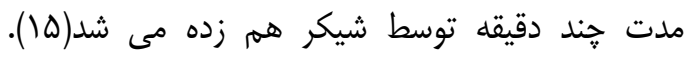

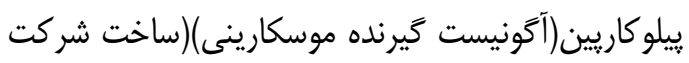
سينا دارو)، در سالين(9/• درصد) حل شده و در حجم نهايى يك ميكروليتر براى هر موش تزريق گرديد.

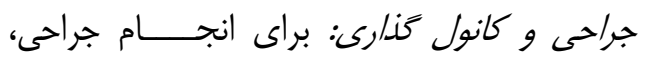

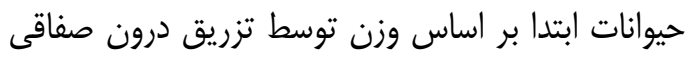

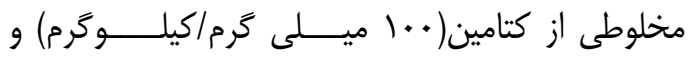

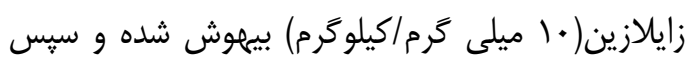
جهت كانول كذارى در دستخاه استريوتكس قرار كرفتند. بعد از ثابت كردن سر حئ ديوان در در دستخاه،

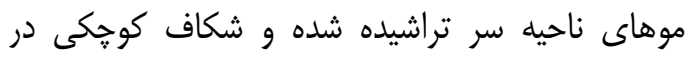
يوست سر در امتداد خط وسط ايجاد كَرديد و به دنبال

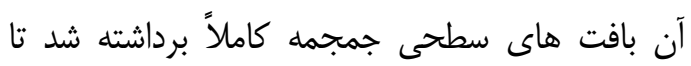

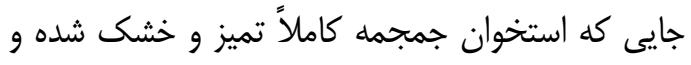

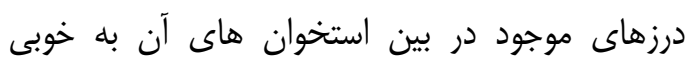

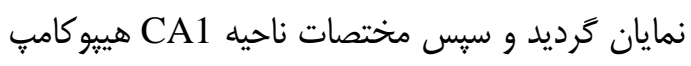

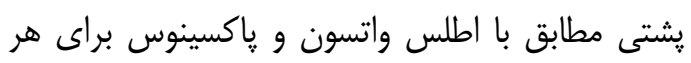
موش تعيين گرديد(ب-ميلى متر فاصله قدامى خلفى

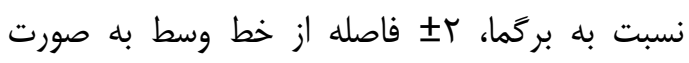
دوطرفه، / T/ فاصله از سطح جمجمهل). نقاط تعيين شده

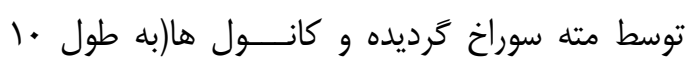
ميلى متر تهيه شده از سرسوزن :زشكى شماره

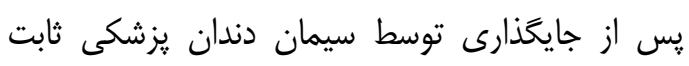

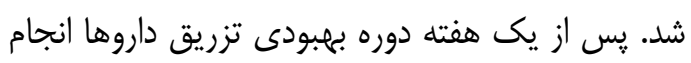

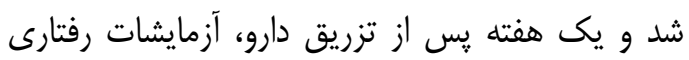




\section{يافته هاى :بزوهش}

اثر تزريق مقادير مختلف نانوذرات اكسيد آهن بروني

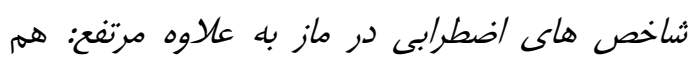

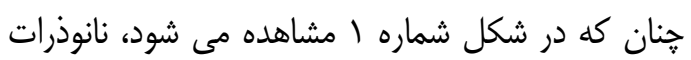

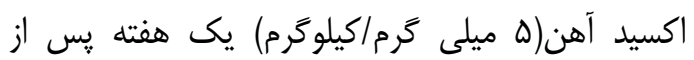

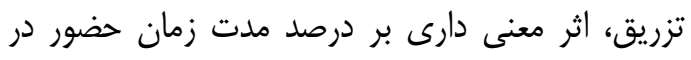

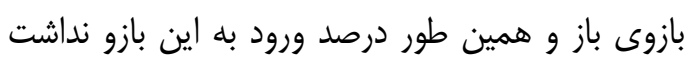

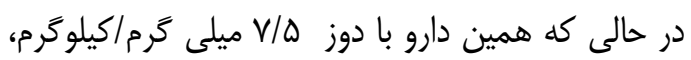
موجب كاهش درصد مدت زمان حضور در بازوى باز و و دارئ

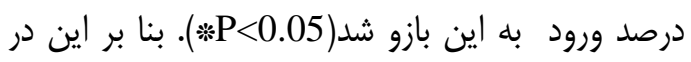

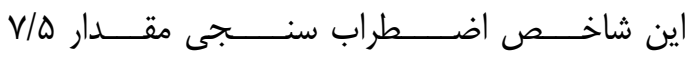

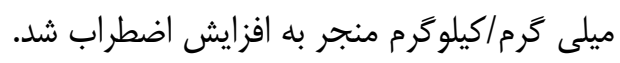

بازوى باز بر مجموع تعداد ورود به بازوى باز و بسته)

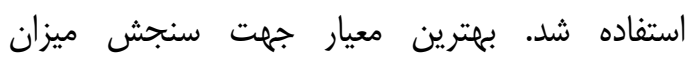

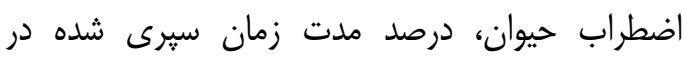

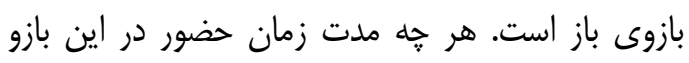

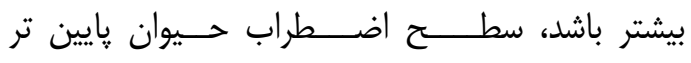
است( •r. بو 19).

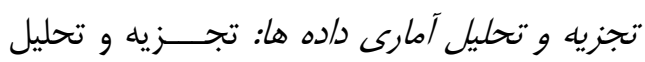

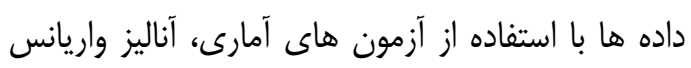

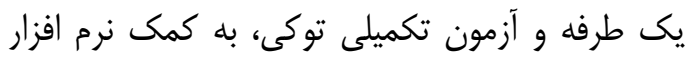

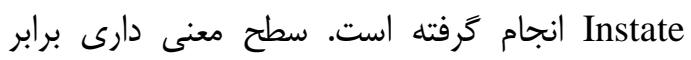

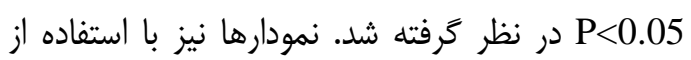
نرم افزار اكسل(EXCEL) رسم شدند.
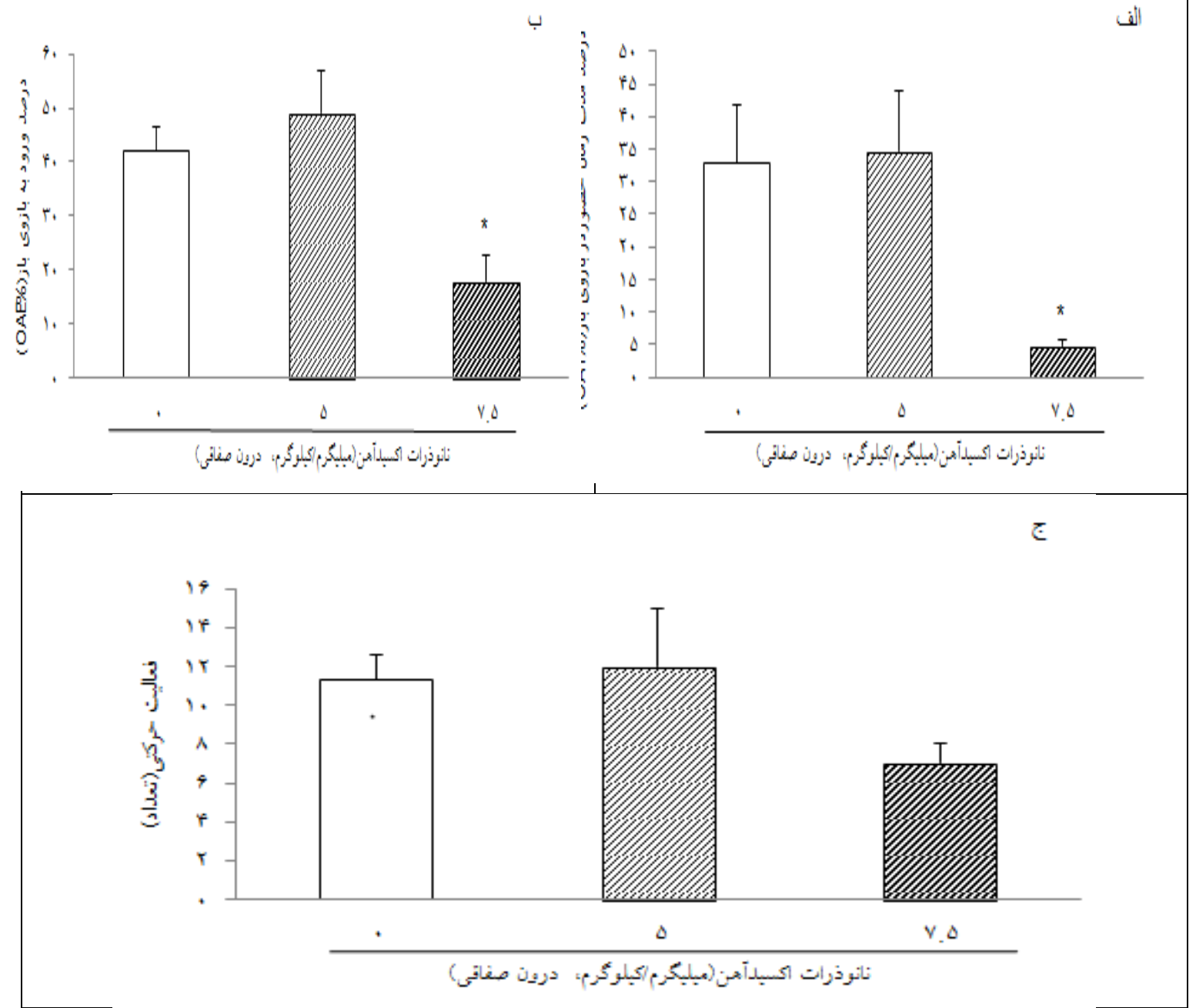

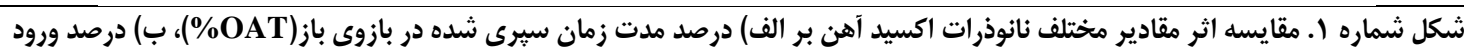

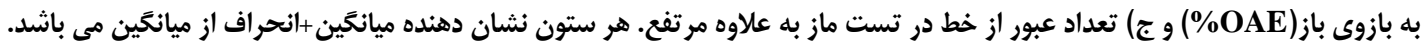
(P>0.05) 
تزريق، تفاوت معنى دارى از نظر درصد مدت زمان حضور

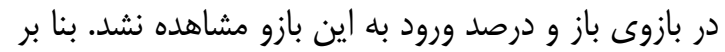

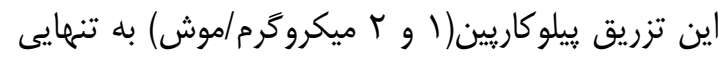
اثر معنى دارى بر شاخص هاى اضطر ابى ندارد.
اثر تزريق ييلوكاربين بر شاخص هاى اضطرابى در ماز به علاوه مرتغع: هم جنان كه در شكل شماره r مشاهده

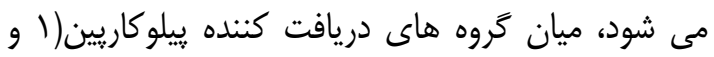

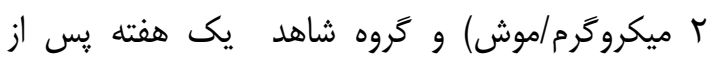
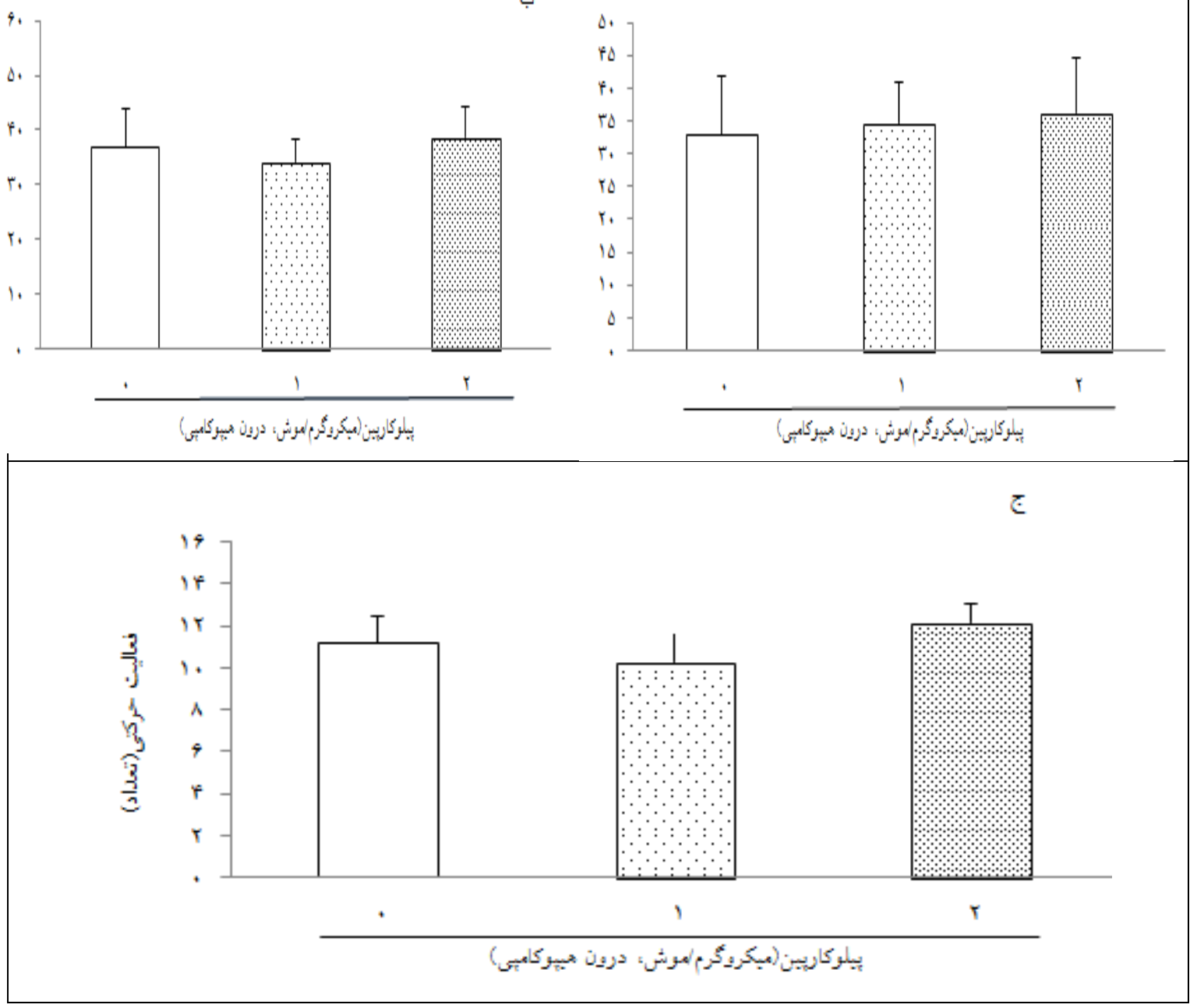

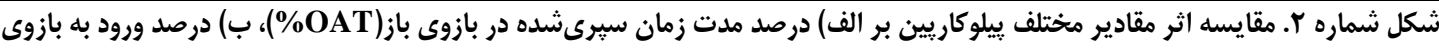

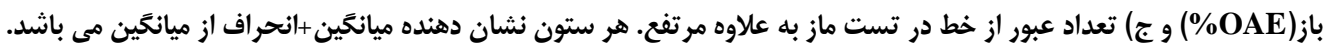

را به تنــــــايى دريـــــافت كـــــده بودند افزايش

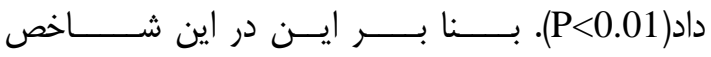

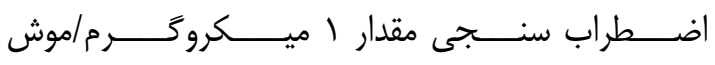

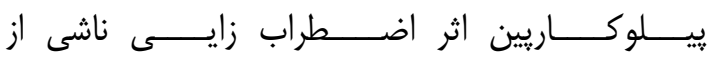

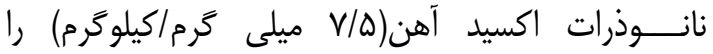

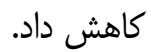

اثر تتريق بيلوكاريين بر اضطراب ناشى از نانواكسيد

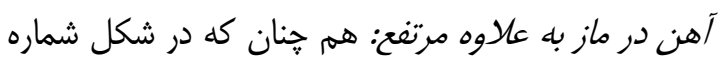

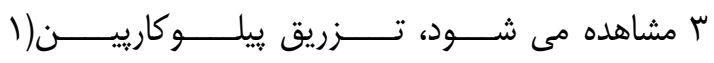

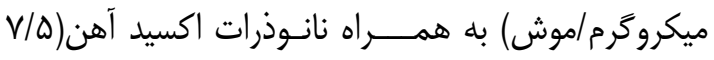

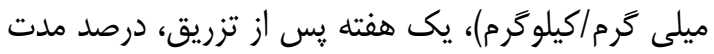

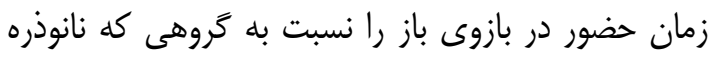




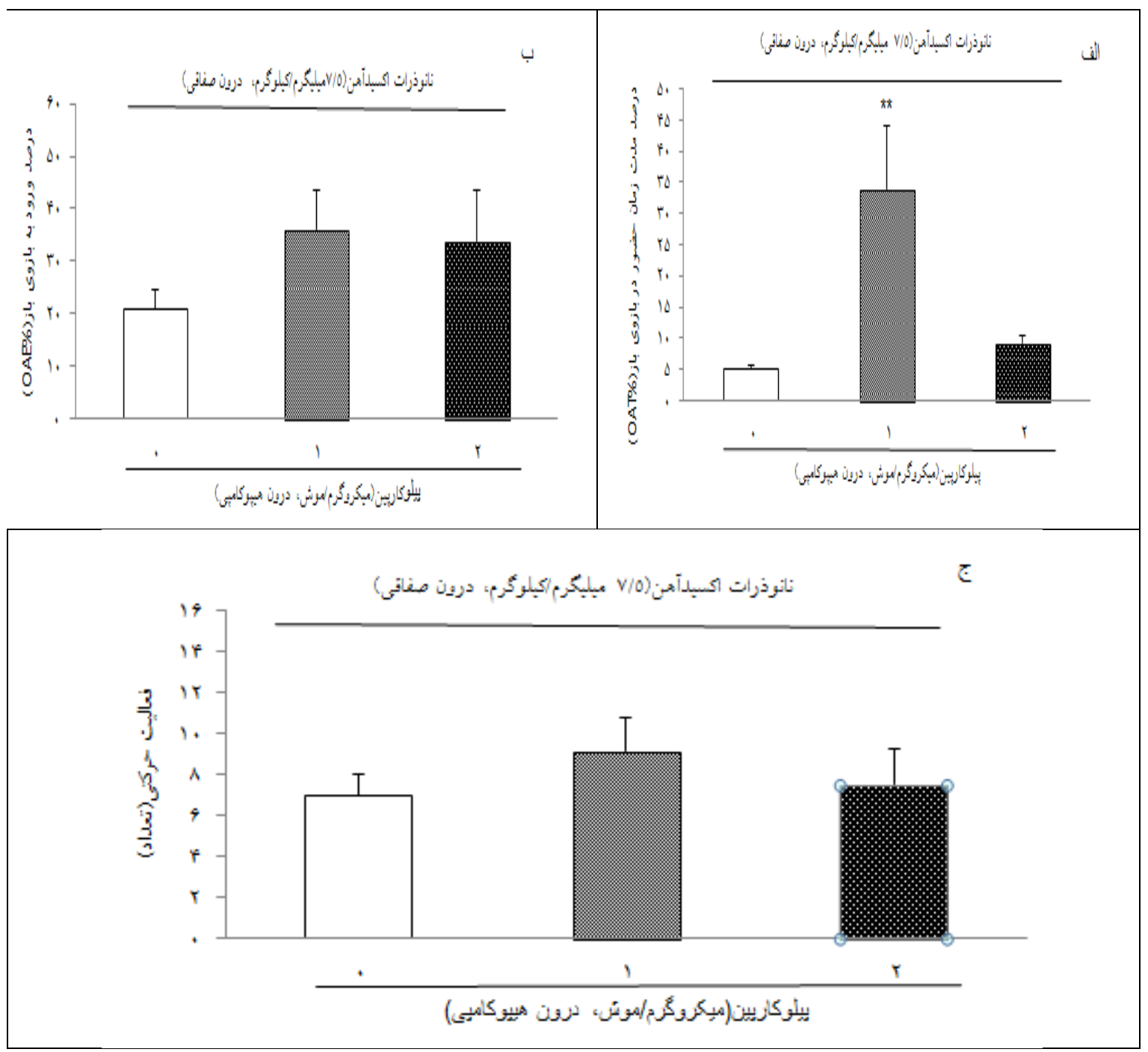

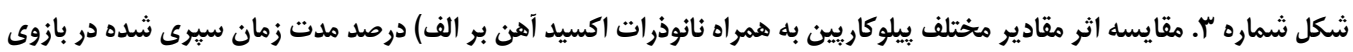

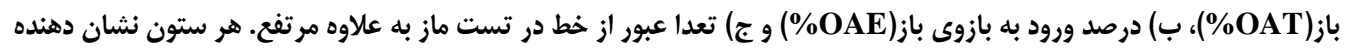

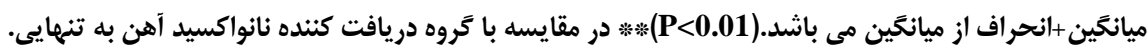

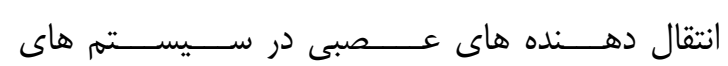

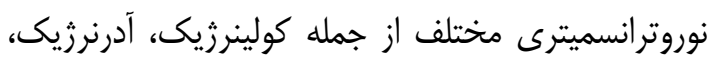

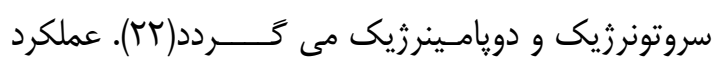

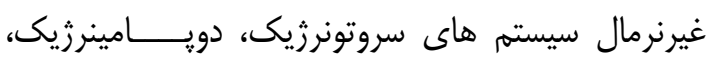

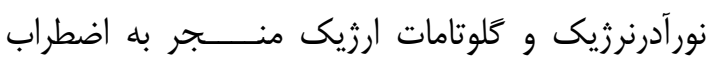

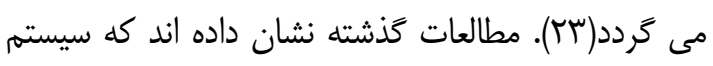

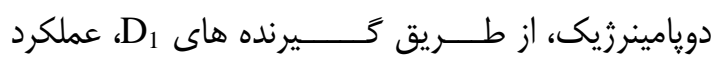

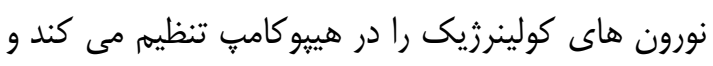

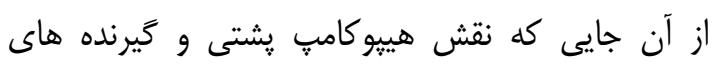

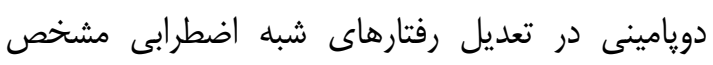

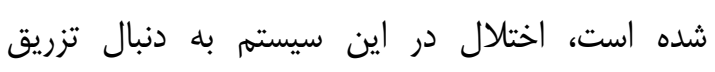
نانوذرات اكسيد آهن نيز به طور غير مستقيم مى تواند بر بر بن

\section{بحث و نتيجه كيرى}

در مطالعه حاضر نشان داده شد كه تزريق نانوذرات

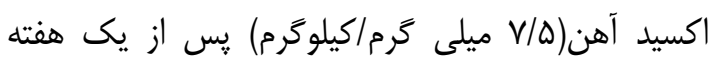

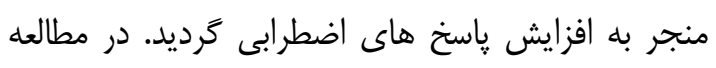

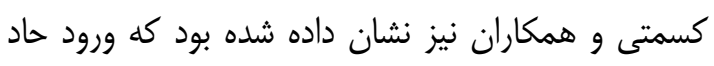

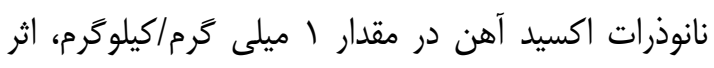

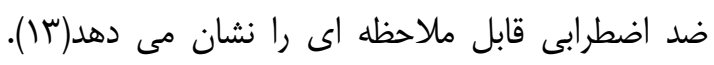

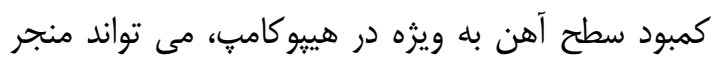

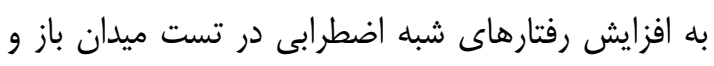

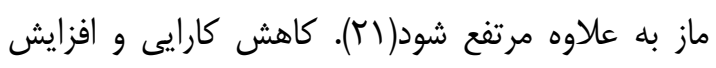

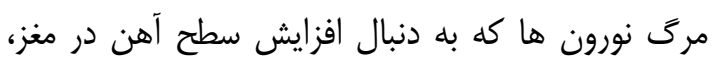

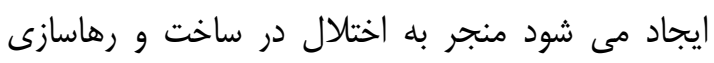


موسكارينى مى شود و بله سبب ارتباط گيرنده هاى موسكارينى كولينرزيك با سيستم هاى نوروترنسميترى از جمله سيستم دويامينرزيك و نورآدرنرزيك در مسير

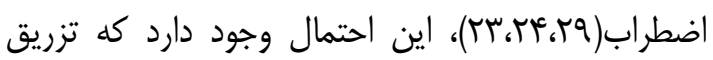
آن به همراه نانوذرات اكسيد آهن توانسته است از اثرات اضطراب زايى اين نانوذرات نسبت به گروهى كه نانوذرات را به تنهايى دريافت كرده اند بكاهد.

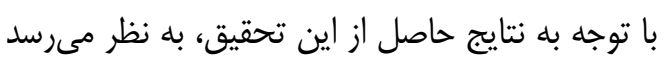

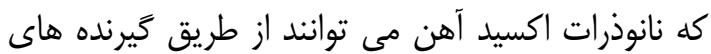
موسكارينى كولينرزيك ناحيه CA1 هييو كامٍ ״شتى در

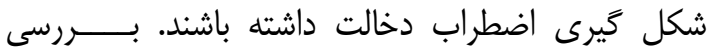
دقيق تر نقش گيرنده هاى موسكارينى كولينرزيك بر اثرات اضطراب زايى نانوذرات آهن نياز به مطالعات بيشتر

\section{سباسگَزارى}

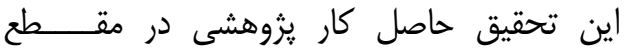

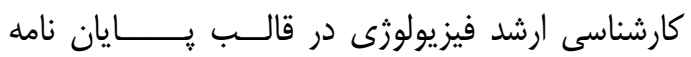

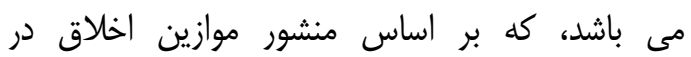
يزوهش، تدوين شده توسط كميته اخلاق يثوهش،

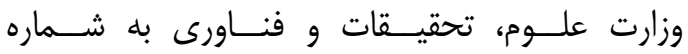

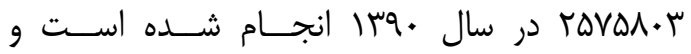
هزينــهـ هاى آن از محل يثروهانه موضع قرار دارد شماره OVY وســــــله از مســـاعدت معاونت محترم يـــــروهشى

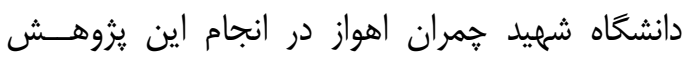

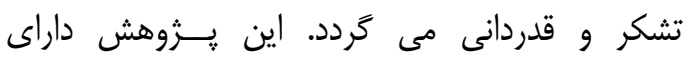
تاييـــAC.IR

\section{Refrences}

1.Hazim AI, Ramanathan S, Parthasarathy S, Muzaimi M, Mansor SM. Anxiolytic like effects of mitragynine in the open field and elevated plus-maze tests in Rats. J Physiol Sci2014 May 1;64:1619.doi.org/10.1007/s12576-014-0304-0

2.Anchan D, Clark S, Pollard K, Vasudevan N. GPR30 activation decreases anxiety in the open field test but not in the elevated plus maze test in female Mice. Brain Behavior 2014;4:51-9.. doi.org/10.1002/brb3.197
عملكرد سيستم كولينرزيك(گيرنده هاى موسكارينى و نيكوتينى) موثر باشد(أب).

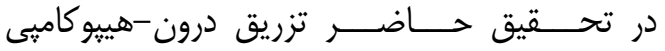

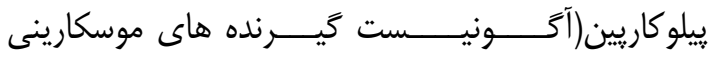
كولينرزيك) كه به تنهايى اثرى بر سطح اضطراب نداشت، موجب كاهش اضطراب القاء شده توسط نانوذرات اكسيد آهن در دستخاه ماز به علاوه مرتفع گرديد(شكل

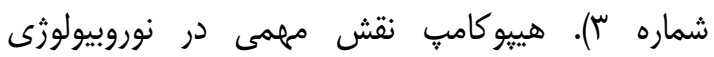
اضطراب ايفا مى كند و با مراكز هيجانى زيادى در مغز مرتبط است. ناحيه CA1 هييوكامٍ پشتى تحت تاثير برخى داروهاى موثر بر اضطراب قرار مى گيرد(م). تغييرات در هييوكامٍ و آميگدال در تمامى اختلالات

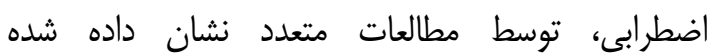

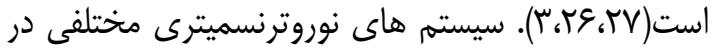
هييوكامي وجود دارند كه در تعديل رفتارهاى شبهاضطرابى دخيل هستند. ورودى هاى كولينرزيك به

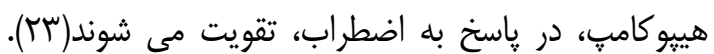
مطالعات بر روى گيرنده هاى موسكارينى كولينرزيك كايك نشان داده است كه تزريق سيستميك اسكويولامين

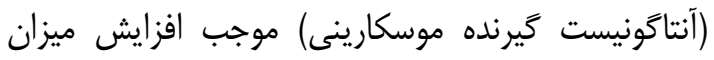
اضطراب در موش صحرايى و موش سورى مى گردد. به عبارت ديگر عملكرد صحيح گيرنده هاى موسكارينى موسى هوني براى تنظيم اضطراب ضرورى است. لى و همكاران نشان دادند كه تحريك و مهار گيرنده هاى موسكارينى، به له ترتيب موجب كاهش و افزايش رفتارهاى شبه اضطرابى

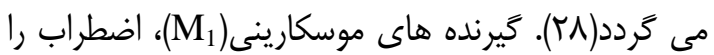
از طريق مسير نورآدرنرزيك تحريك مى كنند(سب). از آن

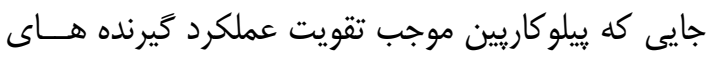

3.Duval ER, Javanbakht A, Liberzon I. Neural circuits in anxiety and stress disorders: a focused review. Therape Clin Risk

Manage2015;11:115.doi: 10.2147/TCRM. S48528

4.Zammit AR, Ezzati A, Zimmerman ME, Lipton RB, Lipton ML, Katz MJ. Roles of hippocampal subfields in verbal and visual episodic memory. Behavir Brain Res2017;317:157-

62.doi.org/10.1016/j.bbr.2016.09.038 
5.File SE, Kenny PJ, Cheeta S. The role of the dorsal hippocampal serotonergic and cholinergic systems in the modulation of anxiety. Pharmacol Biochem Behavior2000;66:65-72.

doi.org/10.1016/S0091-3057(00)00198-2

6.Yakel JL. Cholinergic receptors functional role of nicotinic ACh receptors in brain circuits and disease. Pflu Arch European J Physiolo 2013;465:441-50. doi.org/10.1007/s00424-012-1200-1

7.File SE, Gonzalez LE, Andrews N. Endogenous acetylcholine in the dorsal hippocampus reduces anxiety through actions on nicotinic and muscarinic ${ }_{1}$ receptors.

Behavior

Neurosci1998;112:352.

doi.org/10.1037/0735-7044.112.2.352

8.Wall PM, Flinn J, Messier C. Infralimbic muscarinic M1 receptors modulate anxiety like behaviour and spontaneous working memory in mice. Psychopharmacology2001;155:58-

68.doi.org/10.1007/s002130000671

9.Thomas M, Jankovic J. Neurodegenerative disease and iron storage in the brain. Curr Opin Neurol 2004; 17:437-42. doi:

10.1097/01.wco.0000137534.61244.d1

10. Kim J, Wesslingresnick M. Iron and mechanisms of emotional behavior. J Nut Biochem2014;25:1101-

7.doi.org/10.1016/j.jnutbio.2014.07.003

11. Wu J, Ding T, Sun J. Neurotoxic potential of iron oxide nanoparticles in the rat brain striatum and hippocampus. Neurotoxicology 2013;34:24353.doi.org/10.1016/j.neuro.2012.09.006

12.Dhakshinamoorthy V, Manickam V, Perumal E. Neurobehavioural toxicity of iron oxide nanoparticles in Mice. Neurotoxicit Res 2017;32:187203.doi: 10.1007/s12640-017-9721-1

13.Kesmati M, Khorshidi M. [Effect of $\mathrm{Fe} 2 \mathrm{O} 3$ Nanoparticles on anxiety behavior and nociception in adult male Rat]. $\mathrm{J}$ Kerman Uni Med Sci 2014:21:1-10. (Persian)

14.Bemani-Lirgeshasi S, Khajehpour L, Moazedi AA. [The interaction of cholinergic muscarinic and beta1 Adrenergic receptors of the CA1 region in passive avoidance memory formation in Rat]. J Babol Uni Med Sci 2014;16:22-30. (Persian)
15. Wang B, Feng WY, Wang M, Shi JW, Zhang F, Ouyang H, Zhao YL, Chai ZF, Huang YY, Xie YN, Wang HF. Transport of intranasally instilled fine $\mathrm{Fe} 2 \mathrm{O} 3$ particles into the brain: micro-distribution and chemical states and histopathological observation. Biol Trace Ele Res2007 Sep 1 ; 118:233-43. doi.org/10.1007/s12011007-0028-6

16. Khajehpour L, Rezayof A, Zarrindast MR. Involvement of dorsal hippocampal nicotinic receptors in the effect of morphine on memory retrieval in passive avoidance task. European J Pharmacol 2008; 584:343-51. doi.org/10.1016/j.ejphar.2008.02.030 17.Karimi A, Khajehpour L, Kesmati M. Role of the cholinergic muscarinic receptors of the CA1 area in the memory impairment induced by iron oxide nanoparticle in adult male Rats. Nanomed J2019; 2:73-8. doi. 10.22038/NMJ.2019.13225

18. Khajehpour L, Fathinia K, Moazedi AA, Kesmati M. Beta1 adrenoreceptors of the CA1 area mediate morphine modified state dependent memory in Rats. Neurophysiology2013;45:146-52. doi.org/10.1007/s11062-013-9350-0 19. Torabi M, Kesmati M, Harooni HE, Varzi HN. Effect of intra CA1 and intraperitoneal administration of opioid receptor modulating agents on the anxiolytic properties of nano and conventional $\mathrm{ZnO}$ in male Rats. Cell 2014; 16:163.

20.Torabi M, Kesmati M, Pourreza N, Varzi HN, Galehdari H. Neurobehavioral and biochemical modulation following administration of $\mathrm{MgO}$ and $\mathrm{ZnO}$ nanoparticles in the presence and absence of acute stress. Life Sci 2018;203:72-82. doi.org/10.1016/j.lfs.2018.04.023

21.Texel SJ, Camandola S, Ladenheim B, Rothman SM, Mughal MR, Unger EL, et al. Ceruloplasmin deficiency results in an anxiety phenotype involving deficits in hippocampal iron and serotonin and BDNF. J Neurochem2012;120:125-34. doi.org/10.1111/j.1471-4159.2011.07554

22.Sh A, Khajehpour L, Kesmati M, Najafzadeh H. [Effect of salvia officinalis hydroalcoholic extract on iron oxide nanoparticle induced memory impairment in the presence and absence of beta 
adrenergic receptors in adult male Mice]. J Ardabil Uni Med Sci2016; 15:348-59. (Persian)

23.Kaur S, Singh R. Role of different neurotransmitters in anxiety. Int $\mathbf{J}$ Pharmaceut Sci Res 2017;8:411-6. doi: 10.13040/IJPSR.0975-8232.8(2).411-21

24.Piri MO, Nasehi M, Mafi F, Shahin M, Zarrindast MR. [Interaction between nicotine and dopaminergic D1 receptor of dorsal hippocampus in the hole board test of anxiety]. J Qazvin Uni Med Sci2012;16:44-51.(Persian)

25.Beirami E, Oryan S, Valizadegan F, Zarrindast M. [Performance evaluation of interference morphine and $\beta$-adrenergic system of dorasal hippocampus on anxiety related behaviour in male wistar Rat. J Mazandaran Uni Med Sci2012;22:50-9. (Persian)
26. Irle E, Ruhleder M, Lange C, SeidlerBrandler U, Salzer S, Dechent P, Weniger G, Leibing E, Leichsenring F. Reduced amygdalar and hippocampal size in adults with generalized social phobia. J psychiatr Neurosci 2010;35:126.doi:

10.1503/jpn.090041

27.Baghishani F, Sahab NS. [The role of neurogenesis in anxiety disorders]. $\mathrm{J}$ Shefaye khatam2017;:98-109. (Persian)

28.Li H, Chen L, Li P, Wang X, Zhai H. Insular muscarinic signaling regulates anxiety-like behaviors in rats on the elevated plus maze. Behavir Brain Res 2014;270:256-60.

doi.org/10.1016/j.bbr.2014.05.017

29.Demello N, Junior IQ, Carobrez AP. Pilocarpine prevents age-related spatial learning impairments in rats. Behavior Brain Res2005; 30;158:263-8. doi.org/10.1016/j.bbr.2004.09.006 


\title{
Involvement of Dorsal Hippocampal Muscarinic Cholinergic Receptors of CA1 Area on Anxiety Induced by Iron Oxide Nanoparticles in Adult Male Rats
}

\author{
Khajehpour $L^{l}$, Karimi $A^{l^{*}}$, Kesmati $M^{l}$, Torabi $M^{l}$ \\ (Received: June 20, 2018 \\ Accepted: December 15, 2018)
}

\begin{abstract}
Introduction: Recent findings revealed the biological effects of iron oxide nanoparticles on the central nervous system. Moreover, the brain cholinergic system plays a role in the modulation of anxiety behaviors. Therefore, this study aimed to evaluate the role of dorsal hippocampal muscarinic cholinergic receptors of the CA1 area on anxiety induced by iron oxide nanoparticles in adult male rats.
\end{abstract}

Materials \& Methods: This experimental study was conducted on adult male Wistar rats with a weight range of 200-250 g. All animals were cannulated in the CA1 area using stereotactic surgery. One week after the recovery the intracerebroventricular injection followed by intraperitoneal (IP) injection after $5 \mathrm{~min}$ were administered. Anxiety-like behavior and locomotor activity were performed by elevated plus maze apparatus one week after the injections. The groups were divided into control (saline), iron oxide nanoparticle $(5,7.5 \mathrm{mg} / \mathrm{kg}, \mathrm{IP})$, pilocarpine
(1,2 $\mu \mathrm{g} / \mathrm{rat}$, intra-hippocampal injection), pilocarpine $(1 \mu \mathrm{g} / \mathrm{rat}$, intra-hippocampal injection)+iron oxide nanoparticle $(7.5 \mathrm{mg} / \mathrm{kg}$, IP) , and pilocarpine $(2 \mu \mathrm{g} / \mathrm{rat}$, intra-hippocampal injection)+iron oxide nanoparticle $(7.5 \mathrm{mg} / \mathrm{kg}$, IP). Ethics code: EE/96.24.3.88369/SCU.AC.IR

Findings: Iron oxide nanoparticles (7.5 $\mathrm{mg} / \mathrm{kg}$ ) increased the anxiety level, compared to the control group $(\mathrm{P}<0.05)$. However, pilocarpine injection $(1 \mu \mathrm{g} / \mathrm{rat})$ before iron oxide nanoparticles $(7.5 \mathrm{mg} / \mathrm{kg})$ improved the anxiety induced by iron oxide nanoparticle $(\mathrm{P}<0.05)$.

Discussion \&Conclusions: It seems that probably the anxiogenic effect of iron oxide nanoparticles is mediated through the reduction of dorsal hippocampal muscarinic cholinergic receptor functions in CA1 area.

Keywords: Anxiety, Hippocampus, Iron oxide nanoparticle, Muscarinic receptors, Rat

1. Dept of Biology, Faculty of Science, Shahid Chamran University of Ahvaz, Ahvaz, Iran

*Corresponding author Email:a_karimi_6813@yahoo.com 